\title{
THE PRAGUE AEROSOL CONFERENCE
}

T HE tenth anniversary of the Czechoslovak Academy of Sciences was celebrated by a conference on aerosols attended by 163 national and 56 foreign delegates. The meetings were held during October 8-13, in the Academy's castle at Liblice, near Mèlník, about twenty miles north of Prague (Fig. 1).

The proceedings opened with a series of formal statements on the importance of aerosols in industry, science, agriculture, medicine and meteorology. Prof. K. Spurny, head of the Aerosol Department of the Institute of Physical Chemistry of the Academy, then outlined the development and organization of aerosol research in Czechoslovakia.

The first scientific paper was to have been given by N. Fuchs, of the Karpov Institute of Physical Chemistry, Moscow, but he and several other Russian scientists, who are well known for their work on aerosols, failed to attend although their papers were announced in the programme and no explanation of their absence was forthcoming. It is probable that this occurrence, which is common on such occasions, reflects merely the inability of the overcentralized organization of Communist countries to deal efficiently with the issue of visas and to relax its control of foreign travel.

The programme, listing more than 90 papers, will not be discussed in detail as it is intended to publish the papers and discussions in English some time in 1963; only contributions of a fundamental nature will be considered individually.

Several such papers dealt with fluid motion. Pancev (University of Sofia) used the Kolmogorov theory of isotropic turbulence to show that the root mean square of the difference between particle and air velocity is given by a formula like that for sedimentation under gravity except that $g$ is replaced by the root mean square acceleration of an element of air which is expressible in terms of the energy of turbulent motion. The extent to which particles follow the fluctuations of air flow can thus be specified.

The formation of deposits when an aerosol flows past a step was examined theoretically by Smolik (Prague), who deduced the flow field by a combination of conformal transformation and boundary layer theories, The characteristic pattern of the deposit was shown to be decided by the re-entrainment of deposited particles.

C. N. Davies (London), in a theoretical paper, showed how the sedimentation-rate and inertia of particles, which are being sucked into a sampling orifice from air which is otherwise at rest, reduce the efficiency of sampling.

Present interest in the kinetic theory of transport phenomena in aerosols was displayed by three papers. Podzimek (Czechoslovak Geophysics Institute) calculated the Stefan flow of aerosol particles, concluding that the deposition of small aerosol particles on a water droplet, during its growth by condensation, was important in some meteorological situations; Goldsmith (Harwell), using Waldmann's theory, concluded that the atmospheric scavenging effect of molecular bombardment by condensing vapour was negligible for growing droplets which were around $10 \mu$ diameter.
Two basic effects exist when aerosol particles are surrounded by diffusing vapour; a radiometer force on them, due to uneven molecular bombardment, gives rise to diffusiophoresis and a hydrodynamic drag on the particle is set up by a bulk gas flow which is necessary to preserve constant pressure in a mixture of a gas and a vapour which diffuse at unequal rates; the latter is the Stefan flow and can sometimes exceed the effect due to molecular bombardment.

These problems have been examined in great detail by Deryaghin et al. in Moscow. In his absence, the paper by himself and Bakanov was described by $J$. Pich and proved to contain a new formula for the thermal transport of particles which are large com. pared with the mean free path. This formula purports to explain how it is that thermal precipitators operate some 25 times better than they should, on the old theory, when sampling aerosol particles of high thermal conductivity. In the absence of the author the derivation of the formula could not be explained.

The whole subject is of interest to occupational hygiene because of this and in view of a possible importance in lung deposition of dust where the counterflow of carbon dioxide and oxygen may influence the collection of particles in the alveoli.

The abstracts of the Russian papers which were not delivered showed interest in transport problems. N. Fuchs had a theory of the discontinuities of heat, concentration and velocity, existing in a gas adjacent to an aerosol particle, which covers the difficult range when the particle size is comparable with the mean free path. Prochorov and Leonov were to have described the measurement of the minute force which exists between a pair of evaporating drops and may prevent them from coalescing. This work was also the subject of a paper which was to have been delivered by them at a discussion on the physical chemistry of aerosols held at Bristol in 1960. They were not present and were therefore unable to give a satisfactory account of the remarkable sensitivity that they claimed for their torsion balance when this was queried; the sensitivity claimed at Prague was double the Bristol value.

Another experimental paper, available only in abstract, was by Storozhilova and Deryaghin, and dealt with the lateral displacement of aerosol particles, flowing between parallel plates, due to a crossflow of water vapour causing diffusiophoresis; confirmation of the Waldmann equation for particles small compared with the wave-length was claimed. A flow apparatus, for studying the evaporation of supercooled mists, should have been described by Dukhin, Berezhnaya and Silaev.

The subject of aerosol filtration was introduced by Pich and Binek (Institute of Physical Chemistry, Prague). Since the Brownian motion of particles increases with rise in temperature, while their stop distance, due to gas viscosity, decreases, it is clear that the minimal efficiency of a fibrous filter should shift to a larger particle size at a higher temperature; this was confirmed.

Interesting experimental work by Raduškevič and Kolganov (Moscow) was unfortunately not presented; according to the abstract this was a study of 


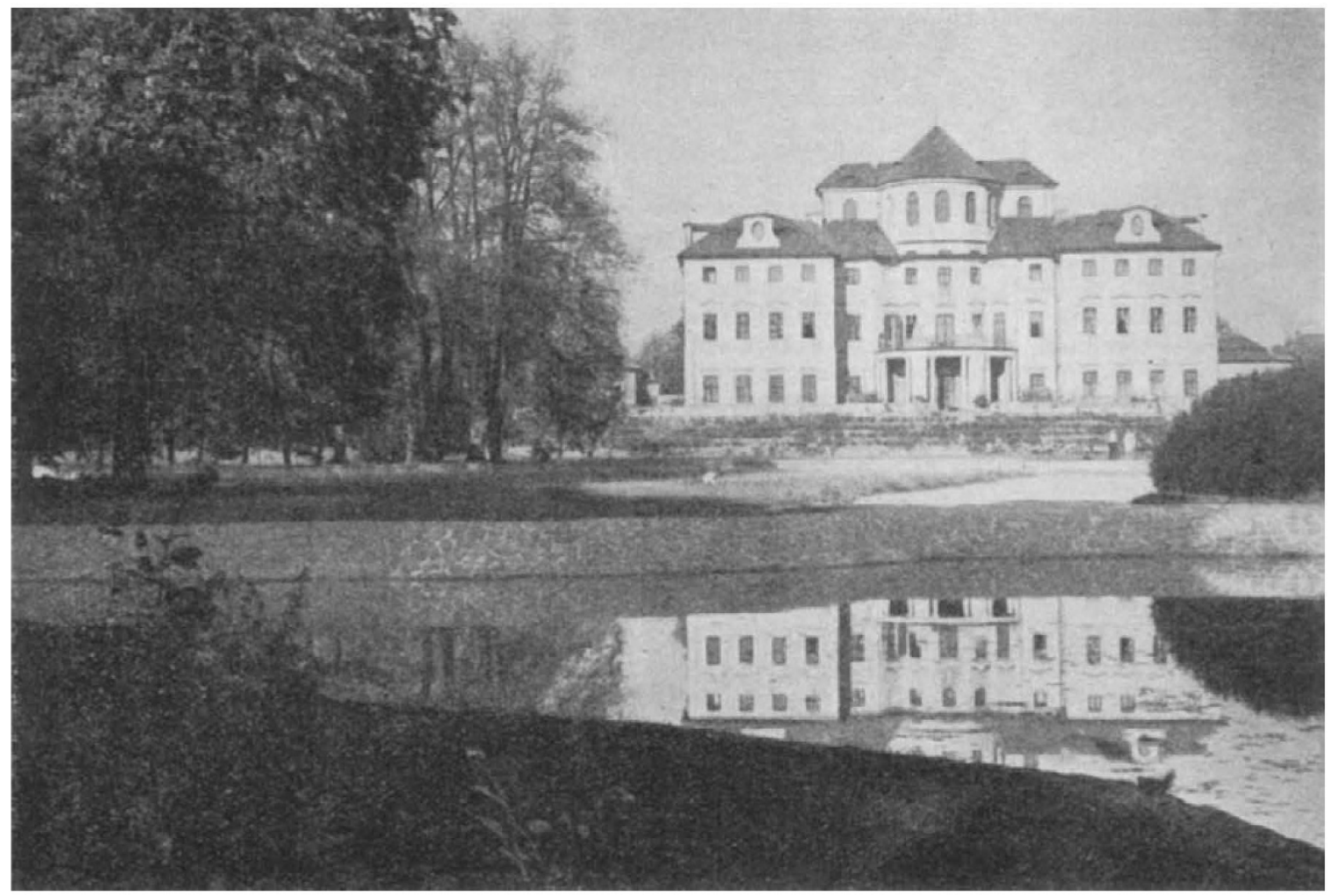

Fig. 1. The castle at liblice which has been adapted for scientific conferences by the Czechoslovak Academy of Sciences

tho deposition of particles between 0.04 and $1 \mu$ in size on individual fibres of asbestos $0.06-0.08 \mu$ thick. Spurný and Pich (Prague) had a capillary model for membrane filters which was used to explain the capture of particles.

Przyborowski (Institut für Staubforschung und radioaktive Schwebstoffe, Berlin) was concerned with the testing of filters and demonstrated the value of pre-filters in plant handling radioactive dust. Lapácek (Prague) gave an account of attempts to develop highly efficient filters capable of controlling the most dangerous radioactive substances to a level of $10^{-46} \mathrm{~g} / 1$. of air.

Electrostatic separation and the use of electric charges to encourage the deposition of aerosols on vegetation were subjects in the paper by Pauthenier and Ponron (Paris). The failure of electrostatic precipitators due to the build-up of an insulating layer of dust and to ionization in the deposit can now be properly accounted for. A new type of centrifugal separator was doseribed by Binek and Pich (Prague).

A whole day was devoted to radioactive aerosols. Results of several series of fall-out measurements were given and various types of recording apparatus were described. An extremely interesting calculation of the dose absorbed, when radon decay products are inhaled was made by J. Thomas (Institute of Hygiene and Oecupational Health, Prague), who made use of the best available data on lung anatomy, mucus thickness and rate of movement by ciliary action, particle deposition and the radioactive transformations, taking into account all factors which could possibly influence the dosnge rate to the respiratory epithe. lium; his conclusions differ very much from previous ideas which have been based on global estimates rather than on an analytical approach.
The deposition of radioactivity on atmospheric particles has been examined by Lassen (Heidolberg). This process is accelerated by their electric charge to an increasing extent for particles smaller than $0 \cdot 1 \mu$. He concludes that 90-95 per cent of natural activity should be deposited on particles less than $0.5 \mu$ and $50-75$ per cent on those less than $0.05 \mu$. Experiments on the deposition of thoron decay pro. ducts were described by Rüger (Institut für Strubforschung und radioaktive Schwebstoffe, Berlin).

Spendlove (Maryland, United States) directed attontion to the possibility of determining the quantities of radioactive dust deposited experimentally in human subjects on the bronchial epithelium and in the alveoli by comparing the excretion-rates; extrapolated back to the time of administration these rates can be determined for gamma active particles with the subject inside a whole-body scintillation counter.

Another day was given to aerosols in meteorology. Goetz (Pasadena, United States) discussed the use of the aerosol spectrometer as an analytical tool and Mészáros (Institute of Meteorology, Budapest) noted that sodium chlorido particles moro than $1 \mu$ in diameter, which he had measured, could be used to identify the origin of air masses. Several speakers from the Meteorological Laboratory at Hradec Králové were concerned with atmospheric nuclei: Vrkočová and Podzimek had gelatine film methods of identifying chlorine and sulphate and membrane filter techniques for ammonium and nitrate; the latter author with Cernoch survoyed flight data; Volfová and Horák found tens of thousands of Aitken nuclei per $\mathrm{cm}^{3}$ in fogs, high concentrations which may be associated, according to Kanf (Jena), with orographical weather. Threo papers dealt with 
meteoric dust. A gelatine film technique for measuring formaldehyde associated with aerosol particles, the first organic substance to be assessed in this way, was described by Lodge and Frank (National Center for Atmospheric Research, Colorado).

The optics of aerosol particles formed the subject of three speakers. Kubie (Institute of Physical Chemistry, Prague) gave a detailed discussion of recent developments in ultramicroscopy; Gucker, Rowell and Chiu (Indiana, United States) presented the results of Mie theory computations for spheres of dioctyl phthalate (refractive index 1.486) which are of value in determining the particle size of uniform mists from measurements of the angular intensity distributions of scattered light; the range of the parameter $\propto$ (circumference of particle/wave-length) was $18 \cdot 0(0 \cdot 1) 23 \cdot 9$. Hodkinson (Safety in Mines Research Establishment, Sheffield) explained the results of his experiments on polydisperse aerosols of irregular particles for which the narrow-angle extinction coefficient can be taken as constant down to quite small sizes depending, in a simple way, on the refractive index.

Eight papers were associated with industrial aerosols and filtration and 18 with agricultural, horticultural and insecticidal applications. The final session of 11 papers dealt with medical treatment by aerosols, including an account of an ultrasonic generator which was stated to deliver into the lungs up to $1 \mathrm{~g}$ of material dispersed as an aerosol in $10 \mathrm{~min}$. Clinical successes in this field undoubtedly require rigorous substantiation.
C. N. Davies

\section{HUMAN POPULATIONS}

\begin{abstract}
$\mathrm{T}$ HE three hundredth anniversary of the publication of John Graunt's Natural and Political Observations made upon the Bills of Mortality, the first book to be published on demography, provided the occasion for a discussion meeting organized by the Royal Society on November 15 and 16, when workers from the biological, medical and social sciences were brought together to discuss problems of common interest in the study of demography. The symposium was financially assisted by the Nuffield Foundation, which made it possible to invite a number of distinguished foreign scholars. Among those attending were Profs. R. Freedman, F. W. Notestein and E. B. Wilson from the United States, Prof. Bernardo Colombo from Italy, Mr. H. Gille from the United Nations Population Division, and Dr. J. Sutter, deputizing for M. Louis Henry of the French Institut National d'Etudes Démographiques. About fifty participants from Great Britain attended the discussion. Responsibility for the organization of the meeting was shared by Prof. D. V. Glass, Dr. P. B. Medawar and Prof. W. S. J. Morgan. 'The papers will afterwards be published in the Proceedings of the Royal Society.
\end{abstract}

The discussion began with a paper by Prof. D. V. Glass, dealing with the life and work of John Graunt. Graunt, a haberdasher by trade, was one of the earliest Fellows of the Royal Society. His election was recommended by the King himself, who particularly charged the Society "that if they found any more such tradesmen, they should be sure to admit them all, without any more ado". After sketching Graunt's life, Prof. Glass turned to an assessment of the significance of his work. He was the first to appreciate the principle of statistical regularity in demographic data; among the subjects in which he was interested were the estimation of the population of London and of Romsey, the examination of mortality differences between town and country, the case fatality of malignant fever, the investigation of infant mortality, and the introduction of the concept of the life table, though it was not until Halley wrote, some thirty years later, that the correct principles of constructing life tables were first understood. Throughout his work, Graunt was meticulous in assessing the reliability and the imperfections of his data, and his discussion of whether rickets was a new disease was a case in point. Although the generalizations he was able to make were of varying degrees of validity and universality, Graunt's work laid the foundations of demography, and of empirical work in the social sciences. His life table, though probably inaccurate at later ages, was of the right order of magnitude so far as infant and child mortality were concerned, a figure of 36 per cent dying before the age of six, being consistent with later experience of societies in a similar stage of development.

In the second paper of the session, Dr. B. Benjamin, chief statistician at the General Register Office, traced the development of the life table, and of mortality analysis in general, from Graunt through the work of Halley on deaths in the city of Breslau, to the Northampton and Carlisle tables of Price and Milne in the eighteenth and nineteenth centuries, and its full fruition in the work of William Farr, who served in the General Register Office from 1837 until 1880. Farr applied the methods of mortality analysis to the study of differentials between town and country, between healthy and unhealthy districts, and fashioned the life table into an instrument of research in the field of disease and public health. In the twentieth century came the analysis of generation mortality, following Derrick's paper, which showed a remarkable parallelism in the movement of age-specific mortality-rates among porsons born in different periods.

More recently, a similar method had been applied to the mortality from lung cancer, a subject on which Mr. Beard reported in the discussion on Dr. Benjamin's paper. $\mathrm{H}_{\Theta}$ found that movements in lung cancer mortality could be well described by regarding it as being made up of three components: the first depending on age, the second depending on the period of birth, which gave an indication of the proportion of smokers in the population, and a third factor depending on the intensity of smoking. This hypothesis aecounted well for the different behaviour of the male and female death-rates from lung cancer.

Another contributor to the discussion, Mr. R. D. Clarke, commented on the curve of deaths, a concept first studied by Karl Pearson. He suggested that it might be fruitful to approach the analysis of mortality by regarding the maximum potential lifespan of an individual as being biologically determined, and that the curve of deaths might be looked at from the point of view of determining the extent to 